Loans, logins and lasting the course: Academic library use and student retention

\author{
Authors \\ Gaby Haddow* \\ Department of Information Studies \\ Curtin University \\ GPO Box U1987 \\ Perth WA 6845 \\ Email: G.Haddow@curtin.edu.au \\ Jayanthi Joseph \\ University Library \\ Curtin University \\ GPO Box U1987 \\ Perth WA 6845 \\ *Corresponding author
}




\title{
Loans, logins and lasting the course: Academic library use and student retention
}

\begin{abstract}
Activities and services that improve student engagement and retention in the higher education sector are important not only to individual student's success but also to university planning and funding. This paper reports on a quantitative study that was carried out to explore whether use of the library by new university students is associated with continued enrolment. Students' socioeconomic background and age were also examined in relation to library use. Limited to commencing students in March 2010 at Curtin University, the study drew on demographic data from the University's enrolment system and instances of library use from the Library's management system. Results of the statistical analyses indicate that library use is associated with retention, and importantly, library use in the early weeks of a student's first semester is associated with retention. 'Mature aged' (21 years and over) students displayed different library use patterns than their younger colleagues and there was some variation in library use between students from different socioeconomic backgrounds. Findings from this study suggest that academic libraries can contribute to the retention of students and that carefully targeted programs and services may improve library use by some groups of students.
\end{abstract}

\section{Introduction}

Engagement and retention of students is becoming increasingly important in the competitive higher education environment and findings from the 2008 Australasian Survey of Student Engagement (AUSSE) report suggest that library use is a factor in improving student engagement. ${ }^{1}$ With data drawn from self-reported library use, including 'using library resources on campus or online' the AUSSE Enhancement Guide for librarians and libraries notes: "There's very strong evidence to suggest that students tend to be more engaged with learning ... if they engage with library resources, interact with library staff, and spend time using libraries". 2 This project focused on one of these factors - engaging with library resources. The specific aims of the study were: to explore if an association between library use and student retention is evident, and to investigate whether socio-economic status (SES) and age at entry are influencing factors in library use and retention.

\section{Background}

Using the language of the time, studies dating back to the early 1970s sought to develop an understanding of 'dropouts' from higher education. Subsequently, the terms attrition, student involvement, student success, retention, persistence and engagement have been employed to describe "the enrolment patterns of students at specific points within postsecondary institutions". 3 In recent years, in Australia and the United Kingdom at least, the preferred terminology has been engagement and retention; engagement referring to "students' involvement in activities and conditions that empirical research has linked with high-quality learning and development"1 and the latter relating to students continuing and completing their studies. Kuh et al. are quoted as saying "what students do" in postsecondary education institutions "counts more 
for what they learn and whether they will persist" than their background or institutional factors. ${ }^{3}$ Engagement, therefore, is regarded as critical to retention.

Clearly, libraries in higher education institutions have a role to play in student engagement and retention. This is acknowledged in the model developed by the 'What works? Student Retention and Success' program, an initiative supported by the Paul Hamlyn Foundation and Higher Education Funding Council for England. ${ }^{3}$ In the model, 'student engagement and belonging' is at the centre of a wheel with spokes reaching out to different institutional systems. One of these systems is 'professional service provision' in which library and learning services reside. The Australian Council for Educational Research has specifically addressed the role of libraries and librarians in their AUSSE Enhancement Guide. ${ }^{2}$ A graph in the Guide plots self-reported library use against ten outcome measures, indicating that all except one (departure intention) of these measures improves with an increase in the frequency of using library resources.

Improving student engagement and retention from a library perspective is the focus of a number of papers looking at different aspects of library services. The provision of library instruction or information literacy programs has been identified as an important contributor to student engagement, ${ }^{4}$ with particular attention paid to minority students in some cases. ${ }^{5}$ Specifically relevant to the research described in this paper is a study, primarily focusing on the role of information literacy as a catalyst, that found that the use of electronic information systems was associated with student retention. ${ }^{6}$ Other studies have employed quantitative analyses to show that there is a strong association between library expenditure and student retention, ${ }^{7}$ and the role of student employment in academic libraries is also discussed. ${ }^{8}$

Research into the use of and preferences for a library's physical space in relation to student engagement is the focus of several papers, ${ }^{9}$ with perceptions of library space by students of different races explored to identify influencing factors. ${ }^{10}$ The provision of targeted library programs to improve retention of minority students ${ }^{11}$ and the contribution of library services to student retention, more generally, are also examined in the literature. ${ }^{12}$

The focus on 'minority' students' engagement and retention relates to US findings that indicate "universities fail to retain African-American, Hispanic, and Native-American students at the same rate as White students" 13 and these results have relevance to this research. In response to the Bradley Review, the Commonwealth Government has announced the intention to provide additional funding to higher education and research to "improve access and outcomes for students from low socio economic backgrounds". ${ }^{14}$ The additional funding is closely linked to helping universities to "provide intensive support to disadvantaged students and improve retention and completion rates". ${ }^{15}$ As a result of this initiative, universities will be looking at ways to develop an environment in which students from low socio-economic status (SES) backgrounds have increased opportunity to engage with the institution and complete their studies.

At present SES is determined by the postcode for the area in which a student resides. ${ }^{16}$ Postcodes are ranked in the Socio-Economic Indexes for Areas (SEIFA) using data collected by the Australian Bureau of Statistics census. It has been acknowledged that this method of classifying SES is flawed and a Discussion Paper was released in 2009 inviting comment on the 
current mechanism for defining low SES and proposals for alternative measures ${ }^{17}$ However, as new measures are yet to be decided or developed, this study used the existing system.

\section{Methods}

In order to achieve the study's aims, enrolment, demographic, and library use data were required for students enrolled in semester 12010 at Curtin University. Enrolment and demographic information relating to commencing students was provided by the University's student database and this was used to identify retained and withdrawn students at the end of semester 1 . Two spreadsheets were generated from the student database. The first listed all new students enrolled at 31 March and the second listed new students enrolled at 26 June 2010. Also included in the spreadsheets were: student ID numbers, postcode, permanent country address, and mature age data. Using the unique student ID numbers, retained students (those listed in both spreadsheets) and withdrawn students (those listed in the first spreadsheet only) were identified.

The Library's management system provided library use data for the commencing students at three points in the semester - 1 April, 15 May and 26 June. Library use data collected for each commencing student were:

- Number of items borrowed (loans)

- Number of logins to a Library workstation (PC logins)

- Number of logins to the catalogue, databases, metasearch tool, and eReserve (Other logins)

Instances of PC logins indicate that students have entered the Library and used a workstation. There is no way of determining if the login was for study or other purposes. Other logins indicate that students have used Library resources and this may be while logged in to a Library workstation or from an external location.

The data generated for library use were extracted as numeric values (for example, 0, 12, 42 instances of PC logins), and this measure of use was included in some analyses. A second measure of 'extent' of library use was developed from the numeric values which were coded into several categories. Somewhat arbitrary, but based on the belief that in a 14 week semester one instance per fortnight for each type of library use is low, the categories for extent of use at 26 June were coded as:

- no use - zero instances of use

- low use - between 1 and 7 instances of use,

- medium use - between 8 and 14 instances of use, and

- $\quad$ high use - 15 or more instances of use.

Extent of library use was also coded for the first point at which data was collected, 1 April. Based on the same view (that is, one instance of library use each fortnight is low) the extent of library use at 1 April was coded as:

- no use - zero instances of use

- low use - 1 or 2 instances of use,

- medium use - between 3 and 8 instances of use, and 
- high use - 9 or more instances of use.

Ethics approval to conduct the study was sought from and granted by nominees of the Curtin University Human Research Ethics Committee. The ethical considerations requiring particular attention were to ensure individual students were not identified or identifiable and the secure storage of data.

\section{The sample}

At the beginning of semester 12010 there were 8,526 new students enrolled in at least one unit. Using the student database spreadsheet of 31 March, Western Australian postcodes were coded as high, medium and low SES using the 2006 SEIFA index. The Index calculates SES on both national and state comparisons. In this study, national SES classes were used for the coding. A number of postcodes had not been assigned an SES level in the Index, for example post office box postcodes, and these were coded as 'no data' and excluded from the sample. Due to the types of library use being investigated, the sample for analysis also excluded students who lived outside the Perth metropolitan area as they had little or no opportunity to visit the campus and login to the Library workstations (PC logins). Students with a permanent country address outside of Australia were not included in the sample because the SES class assigned to their Australian address would not necessarily reflect their true socioeconomic background. Mature aged status is assigned to students who are aged 21 years or older at entry to university.

After excluding students with no SES data, those with a permanent address outside Australia, and those living outside the Perth metropolitan area, the original population of commencing students was reduced to a sample of 4661 for analysis. Of this sample, 194 (4.2\%) students had fully withdrawn from their studies. Figure 1 below compares the percentage of retained and withdrawn students from the sample by SES background and Figure 2 shows the percentage of retained and withdrawn students by age.

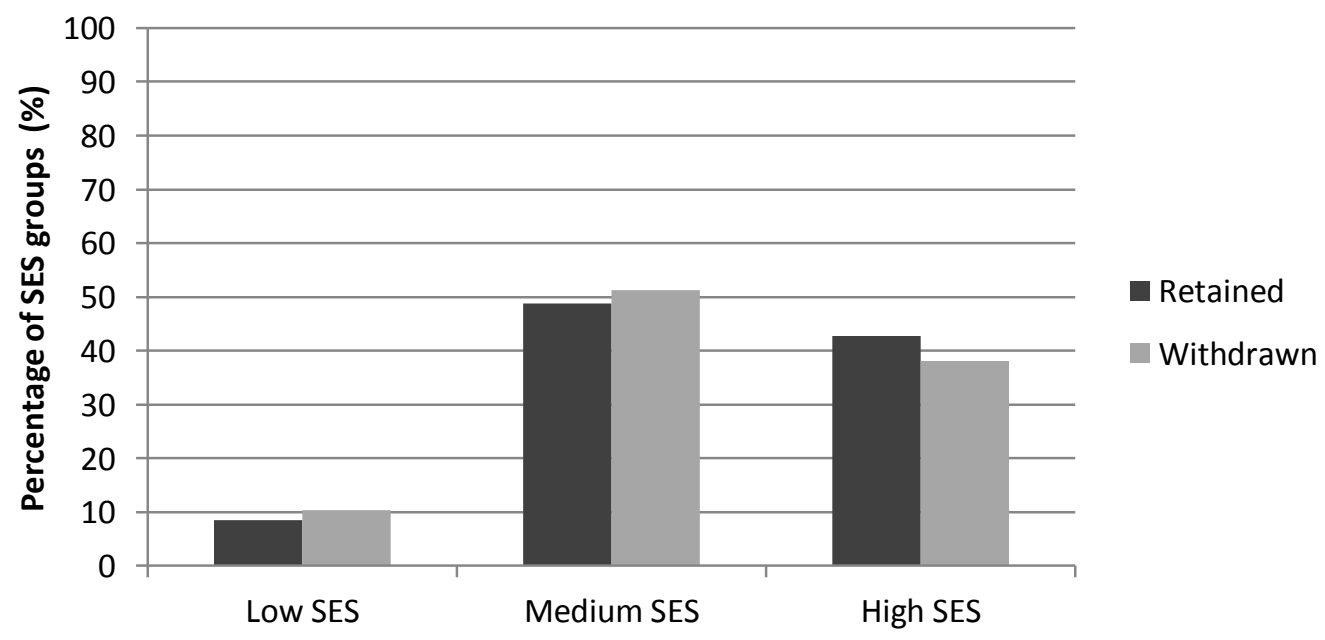

Figure 1: Percentage of retained and withdrawn students by SES background 


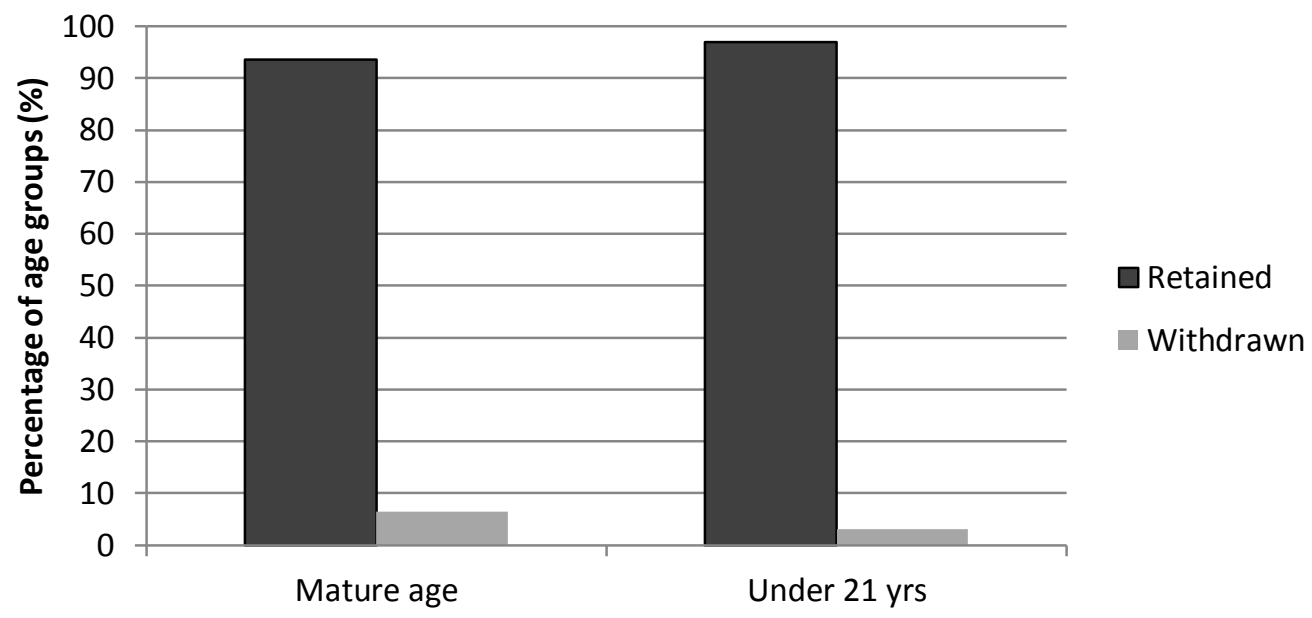

Figure 2: Percentage of retained and withdrawn students by age

The statistical software program SPSS was used to carry out quantitative analyses of the data. In most cases descriptive statistics, such as frequencies and cross tabulations, were used to calculate the extent of library use and retention, SES background and age. The non-parametric test (the Mann-Whitney test) was run to determine associations between the numeric values for library use and the other factors.

\section{Results}

Regardless of whether students had continued in their studies or withdrawn during the semester, a large proportion (64.6\%) had not borrowed items from the Library over the entire period. The results for library use, as indicated by Library workstation logins and logins to other Library resources requiring authentication, by the whole sample showed much higher levels of use over the course of the semester ( $74.6 \%$ and $83.7 \%$ respectively). Figure 3 below displays the results for library use by the whole sample, with the different types of use measured by at least one instance of use. 


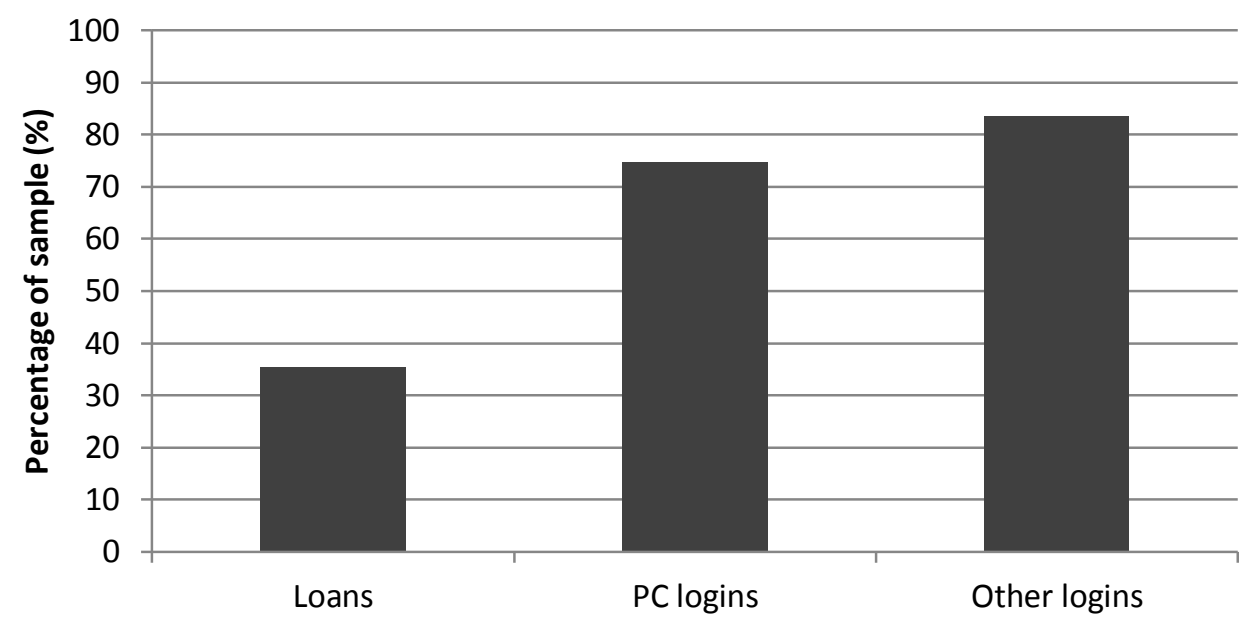

Figure 3: At least one instance of library use by all students

When the three types of library use are analysed against retention at around the middle of semester (15 May) and the end of the semester (26 June) all are statistically significantly associated with retention. That is, retained students showed higher levels of loans, PC logins and other logins. These are not surprising findings as withdrawn students will no longer have access to the resources of the University Library and may have withdrawn several weeks before the data were collected. However, the measures of library use earlier in the semester produced interesting findings. The results indicated no significant differences between the number of loans by retained and withdrawn students, but the other types of library use (PC logins and other logins) were statistically significantly different $(p=.002$ and $p<.001)$ between the retained student group and the withdrawn group at 1 April. In Figure 4 below these results are presented as extent of library use.

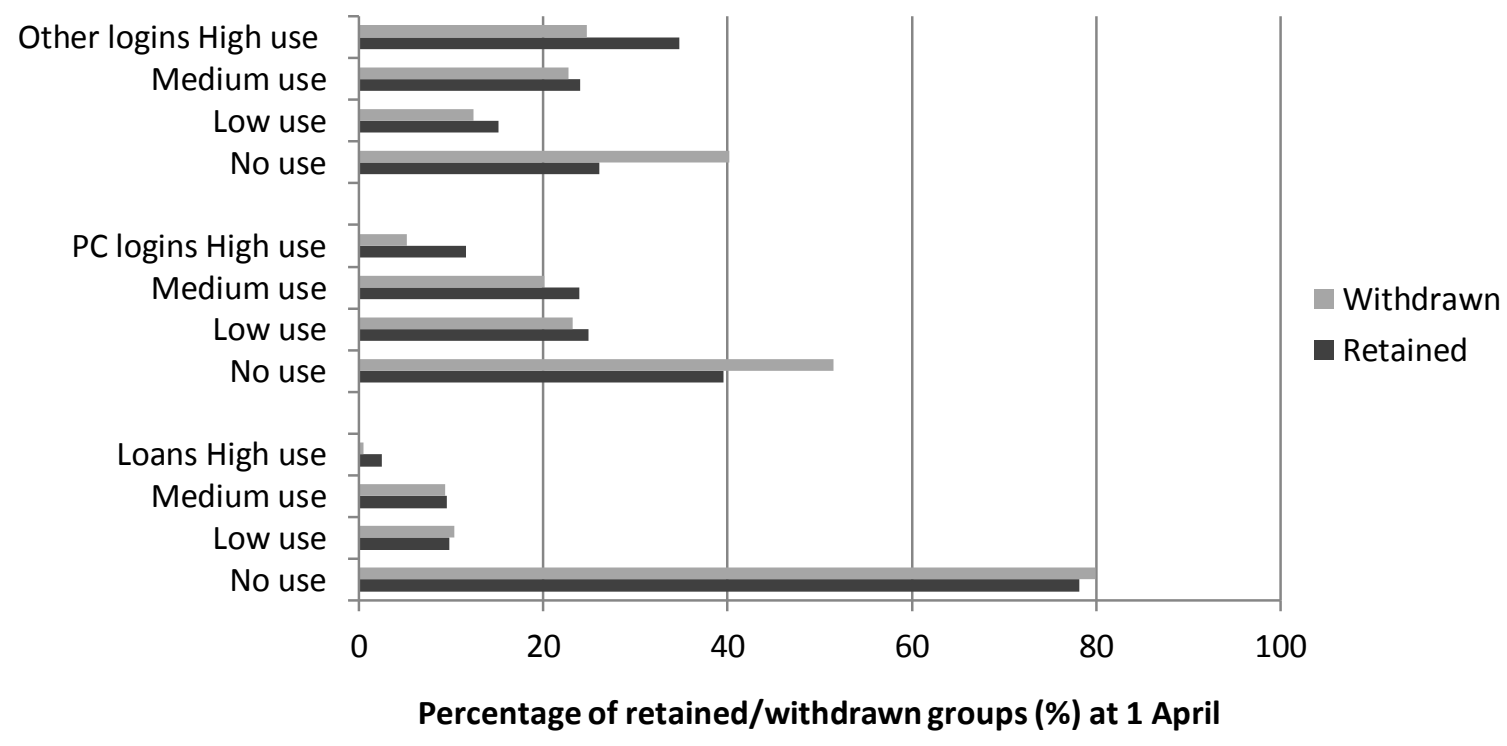


Figure 4: Extent of library use by retention or withdrawal at 1 April

The analyses for different SES backgrounds and library use (across the whole semester) in relation to loans and other logins do not vary significantly between the SES groups. Significant differences were found for students logging in to Library workstations from the low SES group. These students logged into the Library workstations at higher than expected rates and show a significant variation for medium and high use. A similar finding was seen for medium SES students who had more cases of high PC logins than expected. In contrast, there was a higher than expected number of students from the high SES group that have no or low use of Library workstations. The difference between the SES groups and PC logins was statistically significant $(p=.006)$ when the analyses were conducted for use at 1 April. Figure 5 illustrates the extent of the three types of library use by the different SES groups over the semester.

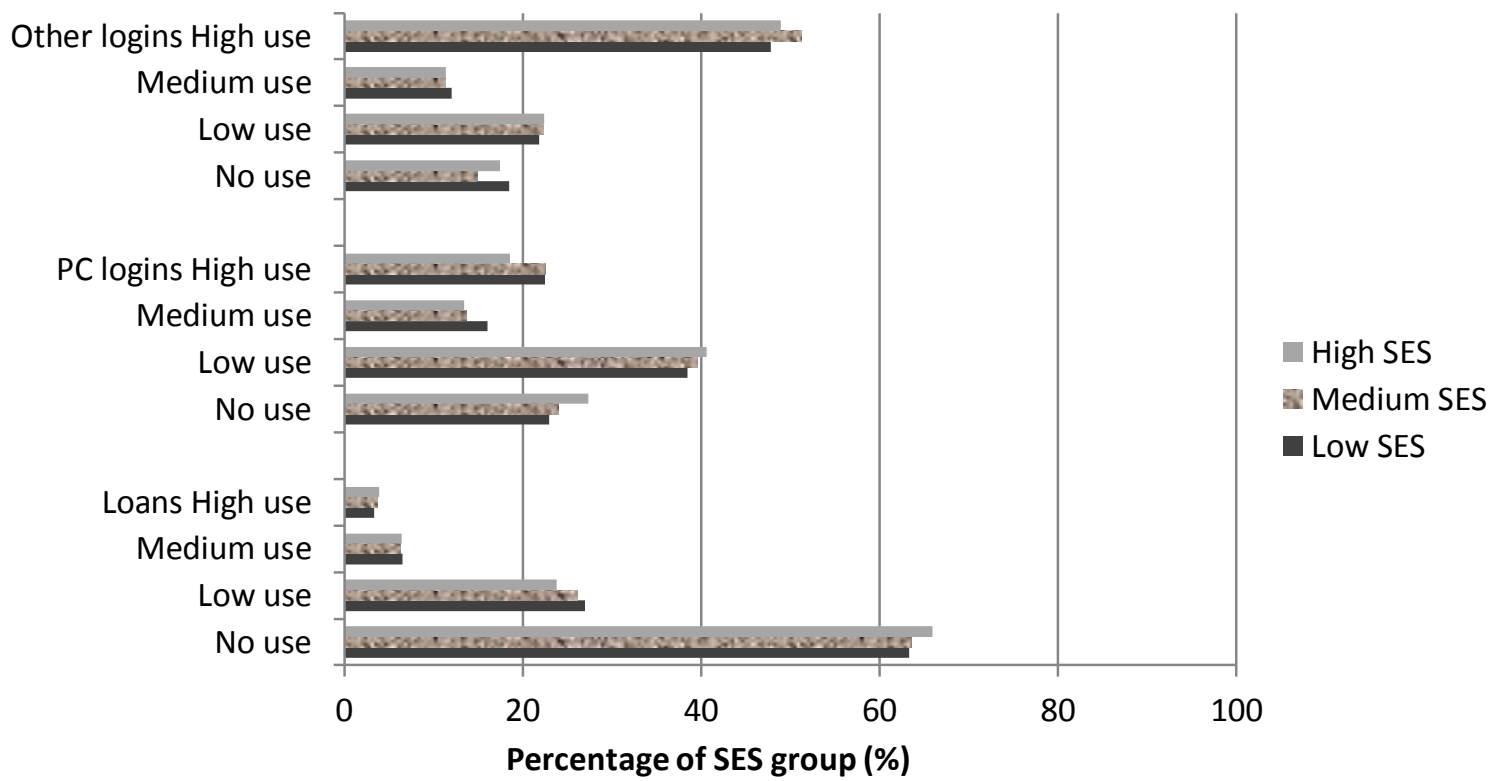

Figure 5: Extent of library use by SES background

Statistically significant differences were found between the library use (for the whole semester) of mature age students and those under 21 years. That is, mature age students borrow books at higher rates than the younger students. This finding was also seen in the analyses for library use in the early weeks of the semester. There are significant differences between mature age students and under 21 year olds for loans $(p<.001)$ at 1 April, and statistically significant differences for PC logins (lower than younger students, $p<.001$ ) and other logins (also lower than the younger students, $p=.001$ ). Figure 6 displays the results for extent of library use by mature aged and nonmature aged students for the whole semester. 


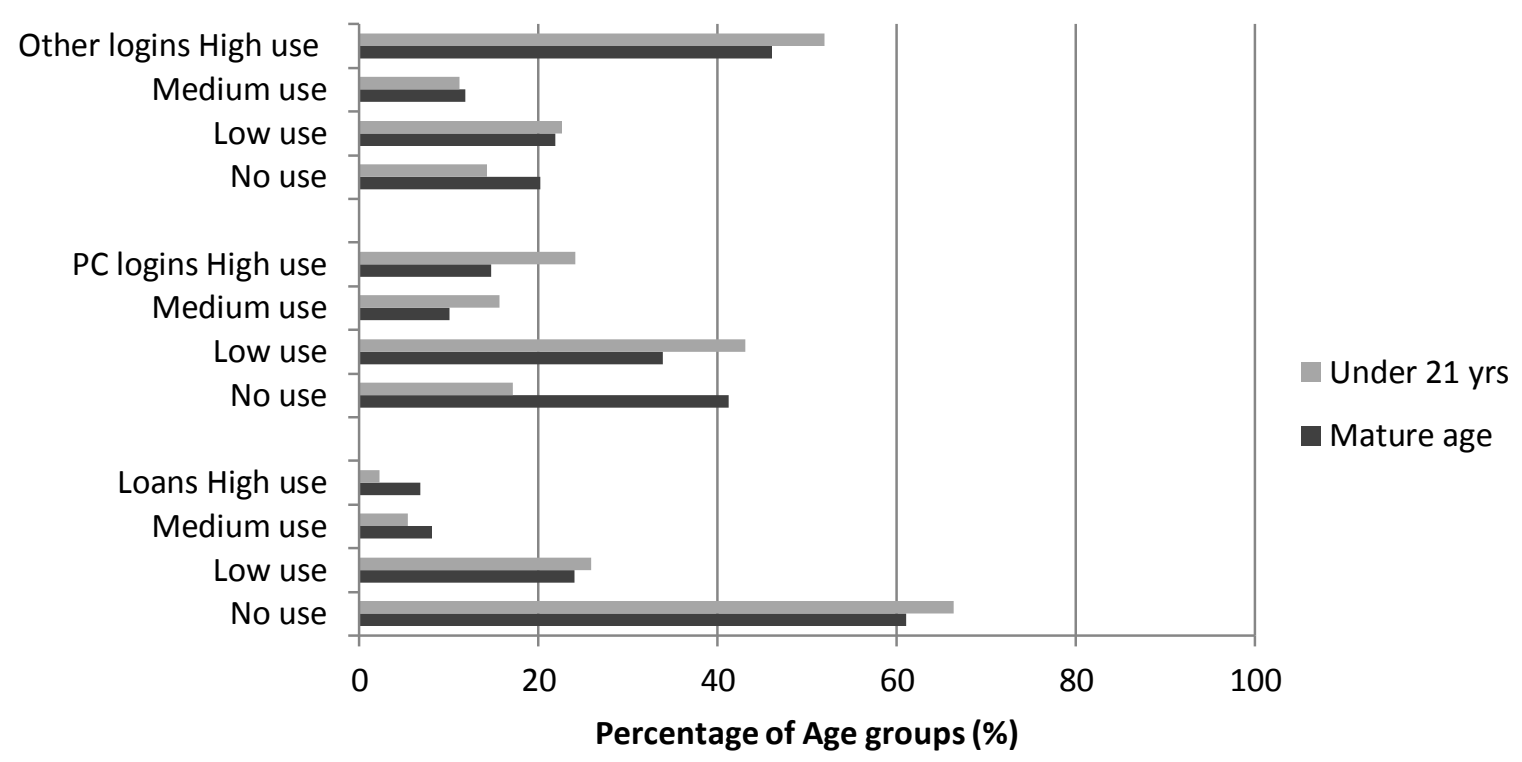

Figure 6: Extent of library use by age

\section{Discussion}

One of the most surprising findings from this study is that many new students to Curtin University are not using the Library, at least not in the traditional sense. Just under two-thirds of the sample of 4,661 students had not borrowed a physical item, such as a book or a DVD, over the semester period. No comparable data was available to determine whether this is a trend which has been occurring over some time or a phenomenon related to this particular group of students. However, as library resources are increasingly being made available electronically, it is probably reasonable to conclude that low loan rates are a casualty of these developments. In contrast, nearly $75 \%$ of the new student cohort had logged into the Library workstations and over $80 \%$ had accessed electronic resources through the Library website. Given the age of most commencing students, these results are not unexpected and they support previous research findings relating to this generation's use of technology. ${ }^{18}$ Considered together, the findings for use of the Library workstations compared with loans provides evidence with which academic library managers can plan for space priorities. With this evidence it may be decided that housing large physical collections will have to make way for additional workstations in the library.

While, logically, student retention was associated with higher levels of library use over the semester, the significant differences found for use of Library workstations and other electronic resources and retention early in the semester may be the most useful results to emerge from the study. It is debatable whether a conclusion can be reached that library use of this type equates to student engagement at university. However, it does appear there is an association between these types of library use and a student remaining enrolled and this has implications for the planning of orientation and information literacy activities. It is also encouraging to find that the relationship between engagement and library use found in the self-reported data from the AUSSE report ${ }^{1}$ is supported by the quantitative data and statistically significant findings of this study. 
A possible explanation for the higher than expected rates of the Library workstation logins by students from low SES backgrounds is that these students may have less access to information technology in their homes. Overall, the differences in library use between the SES groups were not statistically significant over the semester, however PC logins at 1 April were significantly higher for students from low SES backgrounds than their colleagues from medium and high SES backgrounds. Low or no use of the Library workstations by the medium and high SES groups in the early weeks of the semester was also notably higher than for the low SES group. Generally, the findings show that over the course of a semester library use by students from different socioeconomic backgrounds levels out, although there may be some opportunity, early in a semester, for academic libraries to ensure students are aware of the resources, both physical and electronic, available.

Mature aged students display different library use patterns than their younger peers; they have higher levels of loans, but do not use the Library workstations and other electronic resources requiring authentication at the same levels as the students under 21 years. The higher reliance on physical items by mature aged students may be related to less awareness of electronic resources or to a lack of confidence using these technologies. It would be interesting to follow the mature age students through their studies to see if their library use patterns change. In the shorter term, the findings point to a need for targeted information literacy training for mature aged students in the first semester of their university enrolment.

Two additional analyses were conducted to explore if SES background and age were related to retention. These did not include library use as a factor and are therefore not directly relevant to the study. Supporting the findings of previous research, socioeconomic background was not a significant factor in retention in this sample. Mature aged students, however, withdrew from their studies at higher rates than the younger students.

\section{Conclusion}

This study was conceived as a pilot project which would test the methods being applied and identify aspects of library use and student retention to explore in the future. As such, it was limited to only three types of library use and two demographic factors relating to the commencing student sample. The results suggest that there is potential for a larger and longer term quantitative study which could investigate additional demographic characteristics of students (much of this data is readily available in student records systems) and alternative measures of library use to contribute to our understanding of the role of academic libraries in student retention. Further research of this kind may enable library managers to plan, develop and implement programs to meet the challenges of student engagement and retention, and thereby contribute to their institution's success in the higher education sector in the future.

Although limited in its scope, the study has produced a number of interesting findings which have implications for academic library practice. On the basis of the findings it may be necessary for academic libraries to provide additional workstations, which are heavily used generally and appear to be particularly important to students from low socioeconomic backgrounds. Targeted information literacy training for mature aged students in the early weeks of the semester may 
improve their use of the physical and virtual electronic resources available to them in the library. However, the results showed a high proportion of withdrawn students with no or low use of Library workstations and other resources early in the semester, which suggests that training of this kind may be useful for all commencing students. The findings for the low number of loans have longer term implications and these would be understood better if loan numbers were tracked over several years.

The importance of academic libraries in providing support and core services to university students is generally recognised and appreciated by the institutions in which they operate. However, as the institutions come under increasing pressure by government to retain students, and more specifically retain students from previously underrepresented groups in the community, it is crucial to gain an understanding of how the academic library can contribute. This study has presented findings that indicate ways in which this may be achieved, at least in part, and suggests a number of research opportunities to pursue in the future.

\section{References}

1. Australian Council for Educational Research Engaging Students for Success: Australasian Student Engagement Report, Australasian Survey of Student Engagement 2009 at http://ausse.acer.edu.au/

2. Australian Council for Educational Research How Libraries and Librarians Can Support Student Engagement nd. at http://ausse.acer.edu.au/images/docs/AUSSE_EG_Librarians.pdf.

3. Paul Hamlyn Foundation \& Higher Education Funding Council for England Retention Grants Programme: Briefing No. 3. 2010 at http://www.actiononaccess.org/index.php?p=11_3_1

4. PD Boruff-Jones \& AE Mark 'Information Literacy and Student Engagement: What the National Survey of Student Engagement Reveals About Your Campus' College and Research Libraries 2003 vol 64 no 6 pp480-493; C Gibson, C. (ed) Student Engagement and Information Literacy 2006 Chicago, IL Association of Research Libraries; RM Gonyea \& GD Kuh 'The Role of the Academic Library in Promoting Student Engagement in Learning' College and Research Libraries 2003 vol 64 no 4 pp256-282; B Gratch-Lindauer 'Information Literacy-related Student Behaviors: Results from the NSSE Items' College and Research Libraries News 2007 vol 68 no 7 pp432-436; JC Selegean, ML Thomas \& ML Richman 'Long-range Effectiveness of Library Use Instruction' College and Research Libraries 1983 vol 44 no 6 pp476-480; A Stamatoplos 'The Role of Academic Libraries in Mentored Undergraduate Research: A Model of Engagement in the Academic Community' College and Research Libraries 2009 vol 70 no 3 pp235-249. 
5. B Holmes \& A Lichtenstein 'Minority Student Success' College and Research Libraries News 1998 vol 59 no 7 pp496-498.

6. J Crawford \& C Irving 'The Research Agenda' Library + Information Update 2005 vol 4 no 1-2 pp48-49.

7. S. Bell 'Keeping Them Enrolled: How Academic Libraries Contribute to Student Retention' Library Issues: Briefing for Faculty and Administrators 2008 vol 29 no 1 pp14; EM Mezick 'Return on Investment: Libraries and Student Retention' Journal of Academic Librarianship 2007 vol 33 no 5 pp561-566.

8. S Wilder S 'Library Jobs and Student Retention' College and Research Libraries News 1990 vol 51 no 11 pp1035-1038.

9. S Bennett, S 'First Questions for Designing Higher Education Learning Spaces' Journal of Academic Librarianship 2007 vol 33 no 1 pp14-26; D Salinero \& C Beardsley 'Enhancing the Academic Experience: The Library and Campus Engagement' College and Research Libraries News 2009 vol 70 no 3 pp150-152; D Suarez 'What Students do when they Study in the Library: Using Ethnographic Methods to Observe Student Behavior' E-JASL: The Electronic Journal of Academic and Special Librarianship 2007 vol 8 no 3 np; KM Webb, MA Schaller \& SA Hunley 'Measuring Library Space Use and Preferences: Charting a Path Toward Increased Engagement' Portal: Libraries and the Academy 2008 vol 8 no 4 pp407-422.

10. S Elteto, RM Jackson \& A Lim 'Is the Library a "Welcoming Space"? An Urban Academic Library and Diverse Student Experiences' Portal: Libraries and the Academy 2008 vol 8 no 3 pp325-337.

11. E Love 'A Simple Step: Integrating Library Reference and Instruction into Previously Established Academic Programs for Minority Students' Reference Librarian 2009 vol 50 no 1 pp4-13.

12. K Foster 'Libraries and Student Retention: Some Thoughts About the Issues and an Approach to Evaluation' SCONUL Newsletter 2003 vol 28 pp12-16.

13. Love op cit.

14. Department of Education, Employment and Workplace Relations Review of Australian Higher Education: Final Report 2008 at http://www.deewr.gov.au/HigherEducation/Review/Pages/default.aspx

15. Australian Government Funding to Support Low SES Participation Targets n.d. at http://www.deewr.gov.au/HigherEducation/Documents/PDF/Pages\%20from\%20A09303\%20Budget\%20Fact\%20Sheets-2 webaw.pdf 
16. Australian Bureau of Statistics SEIFA: Socio-Economic Indexes for Areas 2008 at http://www.abs.gov.au/websitedbs/D3310114.nsf/home/Seifa_entry_page.

17. Department of Education, Employment and Workplace Relations Measuring the Socioeconomic Status of Higher Education Students: Discussion Paper 2009 at http://www.deewr.gov.au/HigherEducation/Pages/MeasuringSESStatusofStudents.aspx

18. S Gardner \& S Eng 'What Students Want: Generation Y and the Changing Function of the Academic Library' Portal: Libraries and the Academy 2005 vol 5 no3 pp405-420. 